\title{
Situación actual de la leishmaniasis en el Uruguay
}

Current situation of leishmaniasis in Uruguay

Situação actual da leishmaniose no Uruguai

\author{
doi) http://dx.doi.org/10.35954/SM2020.39.1.3

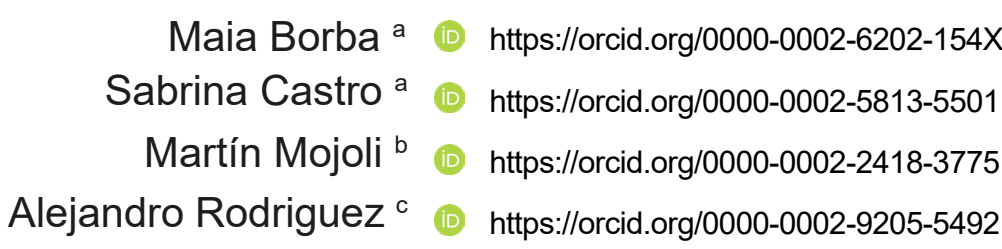 \\ (a) Hospital Quirúrgico Veterinario. Servicio de Veterinaria y Remonta. \\ (b) Servicio de Ginecología. Hospital Central de las Fuerzas Armadas. \\ (c) Jefe del Servicio Coloproctología, Departamento de Cirugía. Hospital Central de las Fuerzas Armadas.
}

\section{RESUMEN}

La leishmaniasis es una enfermedad zoonótica de distribución mundial causada por protozoarios del género Leishmania y transmitida mediante la picadura de un mosquito hematófago ("mosca de la arena") que en América Latina pertenece al género Lutzomyia. Su principal reservorio son los caninos domésticos y silvestres. En el hombre se presenta bajo 3 formas clínicas básicas: formas cutáneas, cutáneo-mucosas y viscerales, siendo esta ultima la de presentación más grave por su alta mortalidad. En los caninos solo se reconoce una presentación clínica, también llamada Leishmaniasis visceral.

Esta enfermedad es endémica en 98 países, principalmente América Latina, África y Asia. Su incidencia y letalidad han venido aumentando de manera preocupante en Argentina, Paraguay y Brasil. En Uruguay en los departamentos de Salto y Artigas se han diagnosticado casos de leishmaniasis canina coincidiendo con la identificación del vector: Lutzomyia longipalpis. En humanos en nuestro país en el año 2018 se diagnosticó el primer caso autóctono. La presente revisión tiene como finalidad ampliar y actualizar los conocimientos sobre la patología, ya que en un futuro cercano deberá ser tenida en cuenta tanto por profesionales veterinarios como médicos e incluida entre los diagnósticos probables de la clínica diaria.

PALABRAS CLAVE: Leishmania; Leishmaniasis/veterinaria; Leishmaniasis Cutánea;

Leishmaniasis Cutánea Difusa.

\begin{abstract}
Leishmaniasis is a globally distributed zoonotic disease caused by protozoa of the genus Leishmania and transmitted by the bite of a blood-sucking mosquito ("sand fly") that in Latin America belongs to the genus Lutzomyia. Its main reservoir is the domestic and wild canines. In humans it presents under 3 basic clinical forms: cutaneous, cutaneous-mucosal and visceral, being the last one the most serious due to its high mortality. In canines only one clinical presentation is recognized, also called visceral Leishmaniasis. This disease is endemic in 98 countries, mainly in Latin America, Africa and Asia. Its incidence and lethality have been increasing in a worrying way in Argentina, Paraguay and Brazil. In Uruguay, in the de-
\end{abstract}


partments of Salto and Artigas, cases of canine leishmaniasis have been diagnosed coinciding with the identification of the vector: Lutzomyia longipalpis. In humans in our country in 2018 the first native case was diagnosed. The present review aims to expand and update knowledge about the disease, since in the near future it will have to be taken into account by both veterinary and medical professionals and included among the probable diagnoses of the daily clinic.

KEY WORDS: Leishmania; Leishmaniasis/veterinary; Leishmaniasis, Cutaneous;

Leishmaniasis, Diffuse Cutaneous.

\section{RESUMO}

A leishmaniose é uma doença zoonótica de distribuição global causada por protozoários do género Leishmania e transmitida pela picada de um mosquito sugador de sangue ("mosca da areia") que na América Latina pertence ao género Lutzomyia. O seu principal reservatório são os caninos domésticos e selvagens. No homem apresenta menos de 3 formas clínicas básicas: cutânea, cutânea-mucosa e visceral, sendo a última a mais grave devido à sua elevada mortalidade. Nos caninos só é reconhecida uma apresentação clínica, também chamada Leishmaniose visceral. Esta doença é endémica em 98 países, principalmente na América Latina, África e Ásia. A sua incidência e letalidade têm vindo a aumentar de forma preocupante na Argentina, Paraguai e Brasil. No Uruguai, nos departamentos de Salto e Artigas, os casos de leishmaniose canina foram diagnosticados coincidindo com a identificação do vector: Lutzomyia longipalpis. Em humanos no nosso país, em 2018, foi diagnosticado o primeiro caso nativo. A presente revisão visa alargar e actualizar os conhecimentos sobre a doença, uma vez que, num futuro próximo, terá de ser tida em conta tanto pelos profissionais veterinários como médicos e incluída entre os diagnósticos prováveis da clínica diária.

PALAVRAS CHAVE: Leishmania; Leishmaniose/veterinária; Leishmaniose Cutânea;

Leishmaniose Tegumentar Difusa.

\section{INTRODUCCIÓN}

La leishmaniosis o leishmaniasis es un conjunto de enfermedades zoonóticas y antropozoonóticas producida por un protozoario parásito del género Leishmania, que cuenta con más de 20 especies diferentes (figura 1).

Se transmite a los humanos por la picadura de mosquitos (flebótomos) hembra infectados. En América, el vector es un mosquito del género Lutzomyia, y en Europa, del género Phlebotomus (1).

Los perros domésticos son los reservorios principales en la transmisión y diseminación de la leishmaniasis urbana, aunque algunos otros animales salvajes, como el zorro y la comadreja, podrían mantener y propagar esta zoonosis en situaciones especiales (2).

Hay tres diferentes manifestaciones clínicas de la leishmaniasis: Leishmaniasis visceral (también conocida como kala-azar), Leishmaniasis cutánea
(LC) y Leishmaniasis muco-cutánea (3).

Es una de las enfermedades parasitarias más importantes a nivel mundial, después de la malaria y la filaria linfática (4).

Se realizó una revisión bibliográfica enfocada en la leishmaniasis en humanos y perros. Las principales bases de datos consultadas fueron MedLine/PubMed, REDVET, Scielo, Science Direct y Scopus $₫$. Incluyendo literatura en español, inglés y portugués, sin límite de tiempo.

\section{DISTRIBUCIÓN GEOGRÁFICA}

La leishmaniasis constituye un problema importante de salud pública debido a su gran impacto, magnitud y brotes epidémicos que ocurren de forma creciente en el mundo ya que a la fecha está presente en los 5 continentes. Es endémica en 98 países, con más de 350 millones de personas en riesgo de transmisión. Se estima que hay 
14 millones de personas infectadas con una incidencia anual de 2 millones de nuevos casos (5). De acuerdo a la Organización Panamericana de la Salud (OPS) se registraron entre 2001 y 2014 en nuestro continente 48.700 casos de Leishmaniasis visceral (6).

\begin{tabular}{|l|l|l|l|}
\hline $\begin{array}{l}\text { Especie de } \\
\text { leishmania }\end{array}$ & $\begin{array}{c}\text { Presentación } \\
\text { clínica }\end{array}$ & Regiones & $\begin{array}{c}\text { Principales regiones } \\
\text { geográficas }\end{array}$ \\
\hline \multirow{2}{*}{ L. infantum } & $\begin{array}{l}\text { Forma visceral y } \\
\text { forma cutánea }\end{array}$ & $\begin{array}{l}\text { Viejo } \\
\text { mundo }\end{array}$ & $\begin{array}{l}\text { Países de la cuenca } \\
\text { mediterránea (Europa, } \\
\text { norte de África y Oriente } \\
\text { Medio) y China }\end{array}$ \\
\cline { 2 - 4 } & $\begin{array}{l}\text { Forma visceral y } \\
\text { forma cutánea }\end{array}$ & $\begin{array}{l}\text { Nuevo } \\
\text { mundo }\end{array}$ & $\begin{array}{l}\text { Argentina, Bolivia, Brasil. } \\
\text { Colombia, Ecuador, } \\
\text { Paraguay, Surinam y } \\
\text { Venezuela }\end{array}$ \\
\hline L. donovani & Forma visceral & $\begin{array}{l}\text { Viejo } \\
\text { mundo }\end{array}$ & $\begin{array}{l}\text { Este de África (Etiopía, } \\
\text { Benia y Sudán), }\end{array}$ \\
\hline L. major & Forma cutánea & $\begin{array}{l}\text { Viejo } \\
\text { mundo }\end{array}$ & $\begin{array}{l}\text { Norte de África, Kenia y } \\
\text { Oriente Medio }\end{array}$ \\
\hline L. tropica & $\begin{array}{l}\text { Forma visceral y } \\
\text { forma cutánea }\end{array}$ & $\begin{array}{l}\text { Viejo } \\
\text { mundo }\end{array}$ & $\begin{array}{l}\text { Norte de África, Grecia, } \\
\text { India y Oriente Medio }\end{array}$ \\
\hline L. aethiopica & Forma cutánea & $\begin{array}{l}\text { Viejo } \\
\text { mundo }\end{array}$ & Etiopía y Kenia \\
\hline $\begin{array}{l}\text { Complejo } \\
\text { L. braziliensis }\end{array}$ & $\begin{array}{l}\text { Forma cutánea } \\
+/- \text { mucocutánea }\end{array}$ & $\begin{array}{l}\text { Nuevo } \\
\text { mundo }\end{array}$ & $\begin{array}{l}\text { Centro América y } \\
\text { Sudamérica }\end{array}$ \\
\hline $\begin{array}{l}\text { Complejo } \\
\text { L. mexicana }\end{array}$ & Forma cutánea & $\begin{array}{l}\text { Nuevo } \\
\text { mundo }\end{array}$ & $\begin{array}{l}\text { Centro América y región } \\
\text { del Amazonas }\end{array}$ \\
\hline Complejo & $\begin{array}{l}\text { Forma cutánea } \\
+/- \text { mucocutánea }\end{array}$ & $\begin{array}{l}\text { Nuevo } \\
\text { mundo }\end{array}$ & $\begin{array}{l}\text { Centroamérica y } \\
\text { Sudamérica }\end{array}$ \\
\hline
\end{tabular}

Figura 1. Presentación clínica y distribución geográfica de las principales especies de Leishmania que afectan a las personas. Adaptado de la Organización Mundial de la Salud (5).

Nuestra región está afectada por la forma visceral (LV) americana producida por Leishmania infantum. Luego de colonizar diversas poblaciones en Paraguay, Argentina y Brasil, alcanzó a nuestro país. En el año 2010, el vector Lutzomyia longipalpis fue capturado por primera vez en los departamentos de Artigas y Salto, y en febrero de 2015 se describieron los primeros casos de leishmaniasis por Leishmania infantum en perros en el departamento de Salto. Ante esta situación de riesgo de inminente aparición de casos humanos, la División de Epidemiología del Ministerio de Salud Pública (MSP) conformó un equipo multidisciplinario, con la participación de la Universidad de la República (UDELAR), para el desarrollo de guías de manejo de Leishmaniasis visceral en el humano, vector, re- servorio y comunicación, destacando los principales lineamientos de actuación en nuestro país (7).

\section{ETIOLOGÍA}

El agente etiológico de la leishmaniasis es un protozoario del género Leishmania, que pertenece al orden Kinetoplastida y a la familia Trypanosomatida. El género Leishmania se divide en dos subgéneros: Leishmania y Viannia, según donde se produzca el desarrollo del parásito en el vector. Los organismos del subgénero Viannia se multiplican en el intestino posterior, a diferencia de las especies del subgénero Leishmania que lo realizan en el intestino medio (8).

Leishmania presenta dos estadios diferentes en su ciclo vital: una forma extracelular (promastigotes) en el huésped invertebrado (flebótomos) y una forma intracelular (amastigote) en el hospedero vertebrado (hombre o perro).

\section{CICLO BIOLÓGICO}

La principal vía de transmisión de L. infantum, al igual que en otras especies de Leishmania es la picadura de flebótomos infectados (figura 2). Cuando se alimentan de sangre de un hospedador vertebrado infectado, los vectores ingieren macrófagos o monocitos con formas amastigotes que se transforman en promastigotes en el intestino del flebótomo, donde se siguen multiplicando. Después de varios días, el vector previamente infectado pica a un vertebrado para volver a alimentarse de sangre, por lo que introducirá, a través de la probóscide, los promastigotes metacíclicos en la piel de un nuevo hospedador canino o humano. El promastigote dentro del nuevo hospedero es fagocitado por macrófago dentro del cual cambia a la forma amastigote cerrando el ciclo (9). Dependiendo de la especie de Leishmania y de las características inmunológicas del hospedero, la infección puede quedar limitada a la piel, o extenderse por vía linfática local, acceder a las mucosas o diseminarse a órganos con elevado contenido en macrófagos como son el bazo, hígado y medula ósea. 


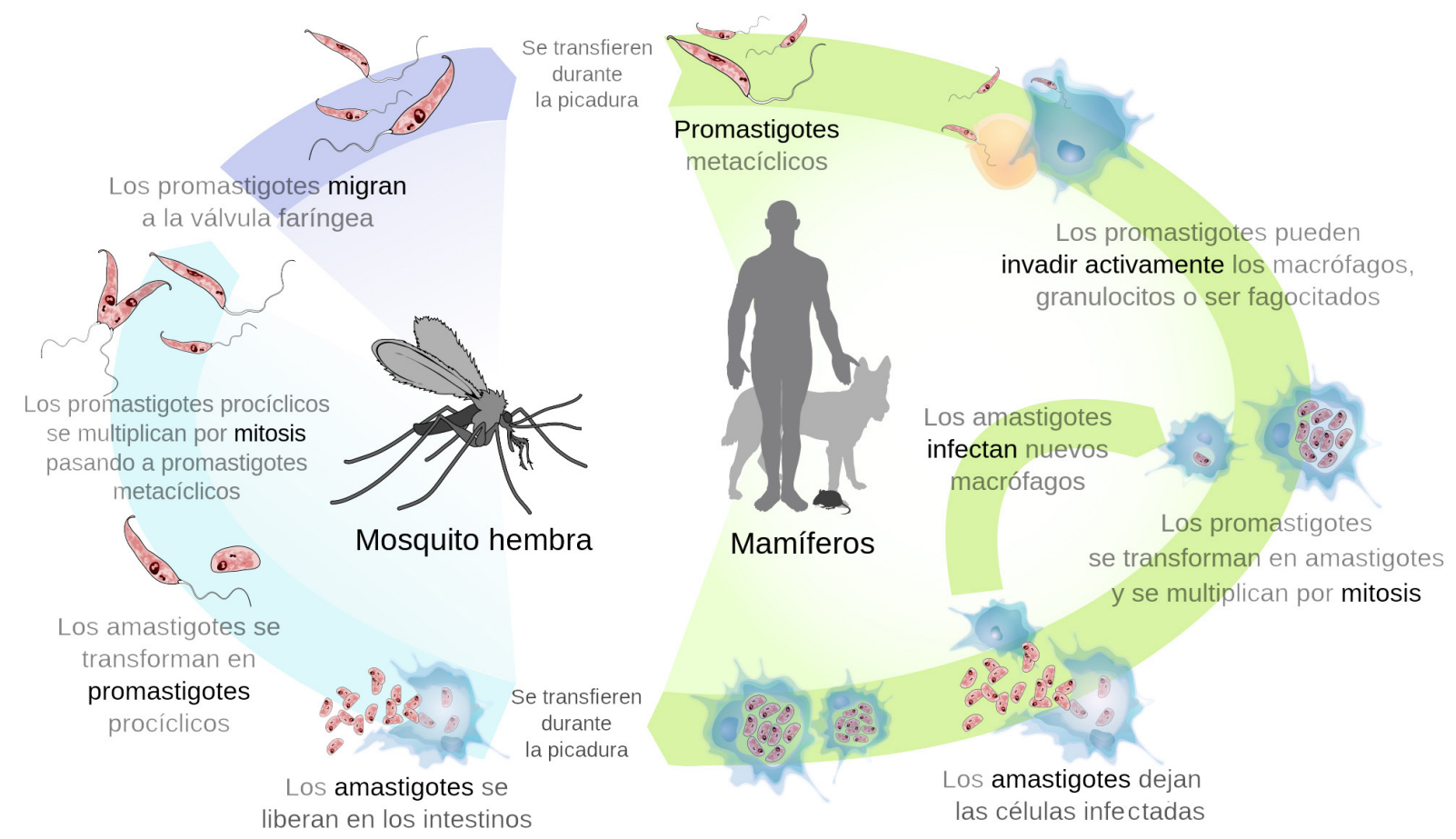

Figura 2. Ciclo vital de los parásitos del género Leishmania, responsables de la leishmaniasis (10).

\section{EPIDEMIOLOGÍA}

La epidemiologia de la leishmaniasis depende de las características de la especie del protozoario, de los aspectos ecológicos de los lugares de transmisión, de la exposición de la población humana y animal al parásito y del comportamiento humano (5).

\section{Factores relacionados a la población humana}

Algunos factores de riesgo están directamente relacionados al hombre, tales como la urbanización, la migración, la deforestación, la mal nutrición y las enfermedades inmunosupresoras. Las deficiencias nutricionales como dietas bajas en proteínas, calorías, hierro, zinc y vitaminas A y D aumentan el riesgo de que la leishmaniasis humana visceral progrese (11). La mal nutrición proteínico-calórica también se ha asociado a un aumento del riesgo de leishmaniosis muco-cutánea.

La coinfección por Leishmania y VIH/SIDA presenta características clínicas atípicas llevando a que los pacientes sufran recidivas, hasta que dejan de responder a la medicación y se caracterizan por poseer una carga parasitaria muy elevada. Los pacientes infectados por VIH/SIDA tienen mayor probabilidad de sufrir Leishmaniasis visceral y a su vez disminuye la respuesta al tratamiento antirretroviral (5).

Las epidemias de leishmaniasis a menudo se asocian con la migración y el desplazamiento de personas a sitios donde ya existen ciclos de transmisión. La exposición en el trabajo y el aumento de la deforestación siguen siendo factores importantes (11).

\section{Factores relacionados al ambiente}

En la mayoría de las regiones endémicas, la enfermedad se caracteriza por una distribución irregular de los focos de transmisión. Esto es debido a las condiciones micro-ecológicas que afectan al vector, al parásito y al reservorio. Dependiendo de cada foco en particular, los cambios en estas condiciones, ya sean naturales o inducidos por el 
hombre, pueden aumentar o reducir la incidencia de la enfermedad. Entre los cambios ambientales que pueden modificar la incidencia de la leishmaniasis se encuentra la urbanización, la domesticación del ciclo de transmisión y el establecimiento de explotaciones agrícolas y asentamientos. En algunas especies de Leishmania la deforestación y destrucción de hábitats naturales de los flebótomos pueden reducir la transmisión de la enfermedad, mientras que en otras la deforestación parece haber aumentado la infección humana en lugar de reducirla. En partes de América del Sur, la deforestación parece haber generado un aumento en la incidencia de la Leishmaniosis cutánea por un cambio hacia el ciclo de transmisión peri doméstico.

La transmisión de la enfermedad está condicionada a factores climáticos como las precipitaciones, la temperatura y humedad. El calentamiento del planeta y la degradación de los suelos afectan en muchos aspectos a la epidemiologia de la enfermedad. Dichos factores climáticos pueden tener efectos importantes en los vectores y los reservorios animales, al alterar su distribución e influir en las tasas de supervivencia y por ende en el tamaño de la población (5).

Se considera que la leishmaniasis aumenta en las zonas de pobreza debido a las malas condiciones de la vivienda y a las deficiencias sanitarias peri domésticas (por ejemplo: la ausencia de sistemas de gestión de residuos, alcantarillado abierto, etc.) que pueden facilitar el desarrollo de los lugares de cría y reposo de los flebótomos y aumentar su acceso a la población humana. Los flebótomos se ven atraídos por el hacinamiento al incrementarse la fuente de ingesta de sangre (11).

\section{Factores relacionados a la población animal}

La presencia de perros dentro de las casas incrementaría, si no se consideran las medidas de prevención, la infección humana, debido a que son los principales reservorios de $L$. infantum. Los gallineros cercanos a las casas pueden ser otro fac- tor de riesgo significativo, pues son un importante lugar de cría, alimentación y reposo de Lutzomyia longipalpis, incrementando así el contacto de los flebótomos, el perro y el hombre (5).

El perro se considera el principal reservorio porque se encuentra en un número elevado en el nicho ecológico, es longevo, está en estrecha relación con el vector y padece la enfermedad de forma crónica, lo que facilita la infección de los flebótomos. El tiempo de exposición de los perros al vector es alto ya que generalmente permanecen muchas horas en el exterior de las viviendas y convive con el humano (12).

\section{LEISHMANIASIS EN HUMANOS}

\section{Definición e historia}

La primera descripción de este parásito fue realizada en 1903, por 2 médicos británicos, llamados Leishman y Donovan, los cuales diagnosticaron Leishmania en el bazo de pacientes humanos en la India. Este parásito se denominó Leishmania donovani, en honor a ellos. En 1908, Nicolle y Comte realizaron la primera descripción en el perro en Túnez. Desde entonces el conocimiento sobre esta patología ha ido avanzando en forma significativa (13).

\section{LEISHMANIASIS EN EL HOMBRE}

La enfermedad se presenta en tres formas principales: Leishmaniasis visceral (también conocida como kala-azar), Leishmaniasis cutánea (LC) y Leishmaniasis muco-cutánea.

Leishmaniasis visceral: en más del $95 \%$ de los casos es mortal si no se trata. Tiene generalmente un curso clínico inicial asintomático, ya que las personas desarrollan una respuesta inmune efectiva. Tienen mayor riesgo de evolucionar a enfermedad sintomática los pacientes con desnutrición, VIH positivos, y los menores de 1 año. Más del $90 \%$ de los casos se producen en menores de 10 años. Las formas de presentación pueden ser asintomáticas, oligosintomáticas o sintomáticas. En las formas asintomáticas el diagnóstico 
es un hallazgo en las pruebas serológicas o de biología molecular, y en las formas oligosintomáticas los síntomas son inespecíficos, presentado los pacientes: debilidad, astenia, adelgazamiento y síndrome febril. En las formas sintomáticas los síntomas son más severos y de mayor gravedad presentando los pacientes síndrome poliadenomegálico, fiebre elevada, hepato-esplenomegalia y síndromes hemorrágicos (figura 3). En cuanto a los análisis paraclínicos se observa: anemia, leucopenia, plaquetopenia, alteración del funcional y enzimograma hepático (13).

Leishmaniasis cutánea (LC): es la forma más frecuente de leishmaniasis. Es de carácter leve, benigno y auto limitado (13). Produce en las zonas expuestas del cuerpo lesiones cutáneas, sobre todo ulcerosas, que dejan cicatrices de por vida y son causa de discapacidad grave. Aproximadamente un 95\% de los casos de Leishmaniasis cutánea se producen en las Américas, la cuenca del Mediterráneo, Oriente Medio y Asia Central. En 2017, más del 95\% de los casos nuevos aparecieron en seis países: Afganistán, Argelia, Brasil, Colombia, República Islámica de Irán y República Árabe Siria. Se calcula que cada año se producen en el mundo entre 600.000 y 1 millón de casos nuevos (11).

Leishmaniasis muco-cutánea: inicialmente afecta la piel y luego se extiende a las mucosas con una importante destrucción parcial o completa de las cavidades oro-nasales, y el tracto respiratorio superior (figura 3). Más del $90 \%$ de los casos se producen en Brasil, Bolivia, Perú y Etiopia (11).

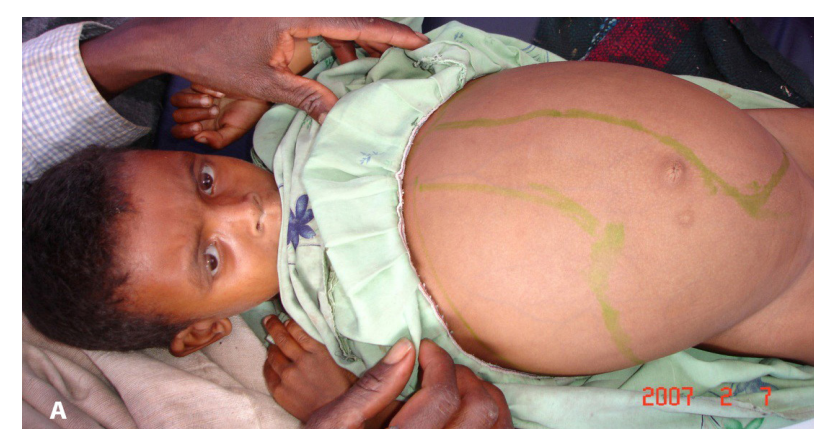

\section{DIAGNÓSTICO}

El diagnóstico de la leishmaniasis se realiza mediante la sospecha clínica y el contexto epidemiológico junto con la combinación de un examen clínico con pruebas parasitológicas o serológicas. Debe ser confirmado microbiológicamente por cualquier técnica parasitológica.

Las múltiples técnicas diagnósticas que se utilizan en nuestro país son:

1) Pruebas parasitológicas directas: que incluyen la detección de parásitos por examen microscópico (frotis).

2) Cultivo: a partir de muestras de aspirado 0 biopsias (ganglio, bazo, etc.).

3) Pruebas serológicas: cuantitativas (ELISA, $A D, I F I)$ o cualitativas (detección de anticuerpos anti-rK39).

Las pruebas serológicas no son definitorias, sino que sus resultados deben ser valorados en el contexto clínico y epidemiológico. El test más utilizado es el ensayo inmunocromatográfico rK39, que detecta anticuerpos en forma cualitativa con base en el antígeno recombinante rK39 propio del complejo Leishmania donovani que incluye a Leishmania infantum. Es una prueba rápida y sencilla de realizar, que tiene valores de sensibilidad y especificidad por encima de $95 \%$. No debe ser utilizado como único criterio para el diagnóstico de leishmaniasis y nunca debe ser utilizado como única referencia para definir un tratamiento. Un resultado negativo no excluye la infección

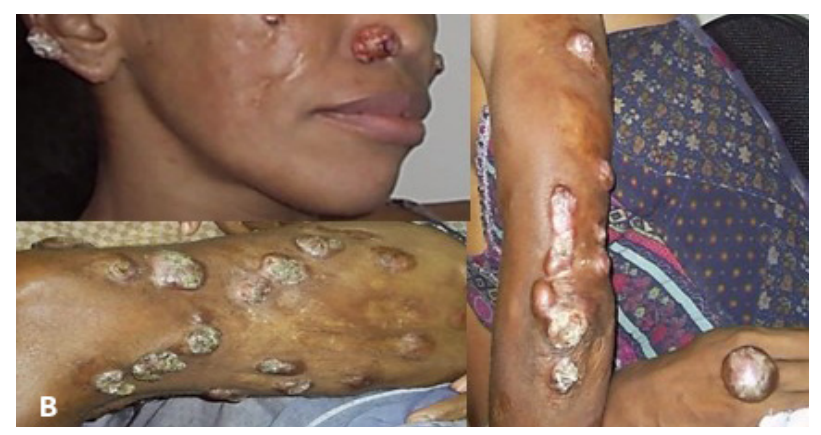

Figura 3. Manifestaciones clínicas en humanos. A) Niña con Leishmaniasis visceral en cuyo vientre se ha marcado el aumento de tamaño del hígado y del bazo (Etiopía). B) Leishmaniasis cutánea difusa: lesiones distribuidas en cara, nariz y pierna izquierda. Polimorfismo lesional en el brazo izquierdo con lesiones en las placas infiltradas (14). 
parasitaria y deben realizarse estudios adicionales. Falsos negativos pueden verse en personas inmunocomprometidas (HIVISIDA y otros).

4) Biología Molecular: detección del ADN del parásito (Reacción en cadena de la polimerasa (PCR)). La PCR presenta niveles de sensibilidad y especificidad cercanas al $100 \%$. En nuestro país se realiza en el Laboratorio de Biología Molecular del Instituto Pasteur.

Dependiendo de la presentación clínica de la enfermedad y de la especie de Leishmania implicada, unos métodos diagnósticos son más validos que otros. Los tejidos de elección para toma de muestra de biopsia o citológicos son médula ósea, ganglios linfáticos y bazo.

\section{TRATAMIENTO EN HUMANOS}

La identificación de la especie causante es fundamental para realizar un tratamiento adecuado (15). El tratamiento puede ser local o sistémico de acuerdo a la forma de presentación de la enfermedad. En las formas cutáneas en donde existen pocas lesiones el tratamiento es local, resectivo (escisión quirúrgica) o destructivo (crioterapia, electro bisturí, calor y aplicación tópica de productos como el Imiquimod). Las lesiones producidas por el tratamiento destructivo pueden ser mayores que la lesión inicial por lo cual a veces se opta por el tratamiento resectivo. El tratamiento sistémico está indicado en aquellos casos en que las lesiones cutáneas son múltiples, en la forma mucocutánea y en la forma visceral.

Los primeros tratamientos han sido en base a los antimoniales pentavalentes (estibogluconato sódico y N-metil antimoniato de glucamina) y la pentamidina. La aparición de resistencia e importante toxicidad farmacológica han dado paso a nuevos tratamientos: anfotericina B liposomal, miltefosina, paromomicina que poseen un perfil más seguro. Anfotericina B $3 \mathrm{mg} / \mathrm{kg} /$ día los días 1 , 5,14 y 21 . En inmunocomprometidos: $4 \mathrm{mg} / \mathrm{kg} / \mathrm{día}$ los días $1,5,10,17,24,31$ y 38 .

Otras opciones terapéuticas son Ketoconazol, Alopurinol y Rifampicina.
En las formas mucocutánea y visceral es necesaria la instauración de un tratamiento adecuado, ya que la enfermedad puede incapacitar, mutilar o matar al paciente (15).

\section{LEISHMANIASIS CANINA}

La leishmaniasis canina es una de las mayores zoonosis a nivel mundial que produce una enfermedad severa a mortal en los perros. Estos, son animales de compañía que se encuentran estrechamente relacionados con el hombre en los países desarrollados como en vías de desarrollo (15). La relevancia de diagnosticar la infección en los perros con o sin manifestaciones clínicas radica en que son los reservorios urbanos conocidos de Leishmaniasis visceral, siendo la principal fuente de infección para los vectores y porque pueden seguir siendo infectantes a pesar del tratamiento que solo mejora su condición clínica. La incidencia en éstos siempre es superior a la de los humanos y usualmente la infección en perros precede a los brotes en humanos (5). El período de incubación en general es de 2 a 6 meses pero puede variar entre 10 días y varios años.

\section{MANIFESTACIONES CLÍNICAS}

Las manifestaciones clínicas de la leishmaniasis canina son muy amplias y variables debido principalmente a los diversos tipos de respuesta inmunitaria que existen en el perro y a la multiplicidad de los mecanismos patogénicos. La infección por L. infantum en los perros es crónica, pudiendo causar tanto una forma subclínica, una enfermedad autolimitante leve o una enfermedad de moderada a grave que puede llevar a la muerte del animal. La clasificación clínica de los pacientes permite establecer las medidas terapéuticas más adecuadas y su correspondiente pronóstico a partir de la gravedad de la enfermedad. El cuadro clínico debe incluir la revisión de los signos clínicos y alteraciones clínico-patológicas, pudiendo existir animales enfermos que, en ausencia de signos clínicos, presentan alteraciones laboratoriales o viceversa (16). 
Los principales signos clínicos incluyen manifestaciones sistémicas y manifestaciones clínicas cutáneas. Se caracteriza por fiebre, hepatoesplenomegalia, linfadenopatía, anemia, leucocitopenia, trombocitopenia, emaciación y debilidad progresivas. Si no se trata la afección clínica suele causar la muerte. La fiebre puede comenzar en forma gradual o repentina y es persistente o irregular. Pero pueden existir pacientes con afecciones de cualquier órgano o tejido, como trastornos renales glomerulonefritis (principal causa de mortalidad), gastrointestinales (diarreas), locomotores, cardiorrespiratorios y neurológicos (encefalitis). Las conjuntivitis y rinitis crónicas son los signos respiratorios de vías altas más comunes en los perros con leishmaniasis (2).

Las alteraciones laboratoriales más comunes incluyen alteraciones hematológicas (leve anemia no regenerativa y leucograma de estrés), alteración del perfil bioquímico (elevación de las enzimas hepáticas, azotemia renal), alteración de las proteínas séricas y de la fase aguda (hipoproteinemia con hiperglobulinemia e hipoalbuminemia), y alteraciones del urianálisis (proteinuria renal). Los hallazgos citológicos e histológicos son inflamación macrofágica, neutrofílicamacrofágica, linfoplasmo celular e hiperplasia de órganos linfoides (17).

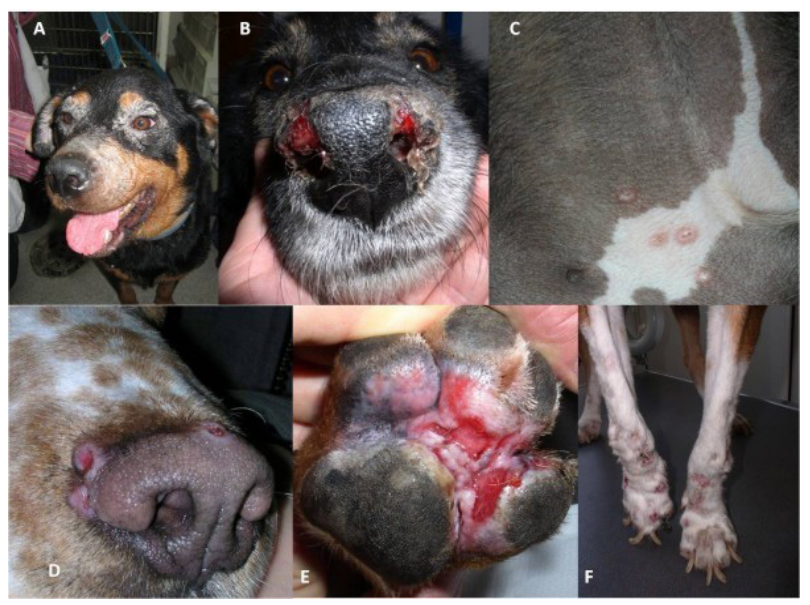

\section{MANIFESTACIONES CLÍNICAS CUTÁNEAS}

Las anormalidades cutáneas son uno de los hallazgos más comunes en perros con leishmaniasis clínicas, presentados aproximadamente en el $80 \%$ de los mismos (18).

Dentro de estas lesiones cutáneas se encuentran aquellas que se consideran típicas (por ejemplo: dermatitis descamativa y dermatitis ulcerativa en las prominencias óseas) o atípicas (dermatitis del plano nasal, dermatitis ulcerativa mucocutánea, alopecia multifocal, entre otras) (figura 4). Gran parte de las anormalidades típicas no presentan mayor problema para el diagnóstico presuntivo de leishmaniasis clínica en perros en regiones endémicas. Pero, por otra parte, las lesiones atípicas pueden ser confusas y retrasar el diagnóstico de perros infectados (16).

\section{DERMATITIS DESCAMATIVA}

El signo clínico cutáneo más frecuentemente observado es la dermatitis exfoliativa no prurítica con un $90,9 \%$ de prevalencia. Las escamas típicas son de tamaño grande, secas, de color blanco nacarado y adheridas a la superficie de la piel. Generalmente se ubican sobre la piel facial, comúnmente en patrón simétrico que incluye el área peri

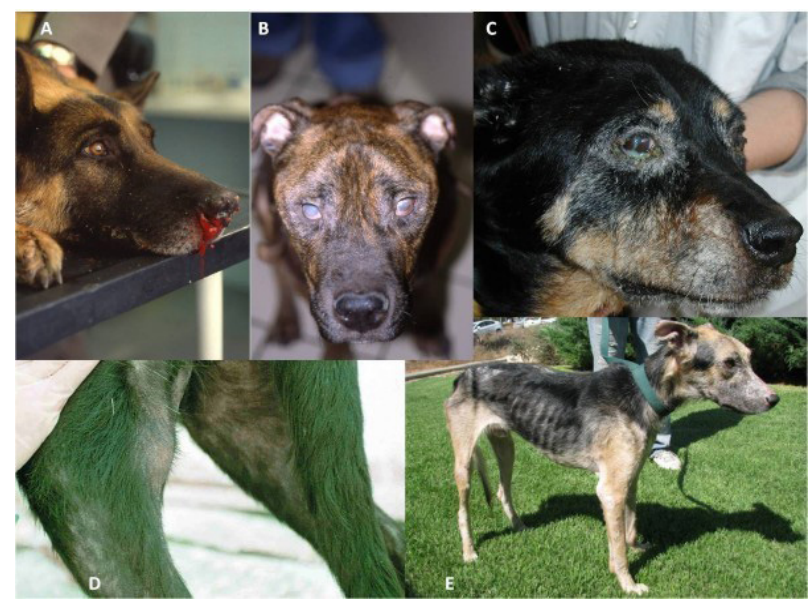

Figura 4. Manifestaciones clínicas en el perro. Imagen izquierda: Diferentes patrones de lesiones cutáneas: A) Alopecia periocular exfoliativa y blefaritis; B) Lesiones mucocutáneas nasales ulcerativas; C) Dermatitis papular en la región inguinal; D) Lesiones crateriformes nodulares que bordean el hocico; E) Lesiones eritematosas ulcerosas en la superficie plantar de la pata y entre las almohadillas; F) Onicogriposis. Imagen derecha: A) Epistaxis; B) Uveítis bilateral y opacidad corneal; C) Conjuntivitis purulenta y blefaritis; D) Alopecia exfoliativa en la pata trasera y linfadenomegalia poplítea; E) Caquexia marcada y alopecia exfoliativa generalizada (22). 
ocular, los pabellones auriculares y la parte dorsal de la nariz. Las escamas pueden encontrarse solo en la cabeza, aunque progresivamente pueden involucrar los cuatro miembros y el tronco. Por lo general, esta descamación precede a la alopecia, que tiende a ser parcial. Si las escamas se encuentran adheridas y no se acompañan de alopecia, pueden palparse en lugar de visualizarse, más que nada en distal de las extremidades. En ocasiones, las escamas pueden estar acompañadas de cilindros foliculares que son acúmulos de queratina estrictamente adheridas a la base del pelo. Los pelos afectados pueden depilarse fácilmente y los cilindros se atribuyen normalmente a la hiperqueratosis folicular (19).

\section{DERMATITIS ULCERATIVA QUE AFECTA LAS PROMINENCIAS ÓSEAS}

Las lesiones ulcerativas costrosas son el segundo tipo de lesiones cutáneas más frecuentemente observadas, encontrándose en un $63,6 \%$ de los perros afectados en áreas localizadas de correspondencia con las prominencias óseas, especialmente en las articulaciones del carpo y tarso (20).

\section{DERMATITIS PAPULAR}

Es un problema dermatológico que, en zonas endémicas, puede considerarse característico y sugestivo de leishmaniasis canina. Se caracteriza clínicamente por la presencia de un número variable de pápulas persistentes, de color rosa a amarillento (en piel pigmentada, por ej.: en labios, aparecen como pápulas despigmentadas), de consistencia aumentada, umbilicadas y distribuidas en zonas sin pelo de perros de pelo corto (cara interna de los pabellones auriculares, labios, párpados, alrededor del plano nasal y abdomen). Las pápulas pueden ulcerarse en la parte central y adquieren la morfología crateriforme descrita como típica de la leishmaniasis cutánea humana (llamado "signo del volcán") (20).

\section{ONICOGRIPOSIS}

La onicogriposis parece ser un problema dermatológico típico de la leishmaniasis canina, ya que no se asocia comúnmente a la leishmaniasis humana. La onicogriposis, se detecta en aproximadamente un $24-90 \%$ de los casos, la paroniquia, en cambio, es menos frecuente (6-14\%) (16).

Clínicamente, la onicogriposis se caracteriza por la hipertrofia y curvatura anormal de las uñas. Dicha alteración se presenta como único signo clínico de esta enfermedad. Sin embargo, la mayoría de los perros con onicogriposis muestran otros problemas cutáneos asociados a la leishmaniasis, especialmente dermatitis descamativa o ulcerativa (21).

\section{DIAGNÓSTICO}

Los métodos diagnósticos usados para la leishmaniasis en animales son:

1. Parasitológico: examen microscópico (frotis) y cultivo (aspirado de nódulos). Podemos usar el diagnóstico histopatológico si la Leishmania está presente.

2. Serológico: debido a que el perro enfermo clínicamente desarrolla altos niveles de anticuerpos circulantes, los test serológicos son una herramienta importante para el diagnóstico.

Los test serológicos usados son:

- Test de fijación del complemento

- Test de hemoaglutinación indirecta

- Test de aglutinación en látex

- Test de aglutinación directa

- Contador inmunoelectroforesis

- Inmunofluorescencia indirecta

- ELISA (Enzyme-linked immunosorbent assay)

- Inmuno ensayo oro coloidal

- Western blot

- IFAT (Immunofluorescence antibody test)

Estas técnicas se diferencian en el tipo de antígeno de Leishmania utilizado. En general IFAT (considerado el "gold standard"), ELISA, test de aglutinación directa y Western blot dan los resultados más satisfactorios. Cuando evaluamos los resultados serológicos debemos tener en cuenta que la detección de anticuerpos positivos puede 
no significar que el animal tenga la enfermedad y constituir sólo un indicativo del contacto con el parásito. Este es el caso de los perros curados clínicamente que podrían tener todavía parásitos circulantes meses después de la enfermedad.

Los test serológicos no son $100 \%$ sensibles. Los animales en fases tempranas de la enfermedad pueden ser seronegativos.

3. Kits comerciales: para la detección rápida de anticuerpos se usan mucho. Estos kits consisten en ensayos inmunocromatográficos que emplean anticuerpos monoclonales IgG anticaninas marcados con oro coloidal, y el antígeno de la Leishmania de diferentes fuentes.

4. Biología molecular: reacción en cadena de Polimerasa (PCR). Esta técnica es muy útil para el diagnóstico, el seguimiento de los pacientes durante y después del tratamiento y la identificación de la especie de Leishmania.

\section{La detección del ADN de la Leishmania: es} posible en la médula ósea y los aspirados de los nódulos linfáticos al igual que en sangre. La sensibilidad y especificidad de este método es tan alta que los parásitos pueden ser detectados en pacientes que han estado clínicamente sanos durante varios años (22).

\section{TRATAMIENTO}

Los fármacos de elección son los derivados de amonio pentavalentes en particular el antimoniato de n-metil glucamina, (80-100 mg/kg/día, por vía intramuscular o subcutánea), Alopurinol (20 mg/kg/ día, por vía oral) y la Anfotericina B (desoxicolato o formulaciones lipídicas).

Las recidivas tras el tratamiento son frecuentes. En zonas endémicas, los métodos de control recomendados consisten en un tratamiento rápido de los perros infectados y un control de los perros vagabundos abandonados. El tratamiento de los perros de áreas no endémicas es cuestionable y probablemente inadecuado. Por el momento, no existe una vacuna eficaz contra la leishmaniasis canina (23).

\section{SITUACIÓN ACTUAL EN URUGUAY}

En Sudamérica la leishmaniasis es endémica y la especie predominante es la Leishmania infantum. La epidemiología de la Leishmaniasis cutánea en las Américas es muy compleja, pues se observan variaciones en los ciclos de transmisión, los reservorios, los flebótomos vectores, las manifestaciones clínicas y la respuesta al tratamiento. Además, hay varias especies de Leishmania en la misma zona geográfica. Brasil concentra el 90\% de los casos de Leishmaniasis visceral (11). Existen tres escenarios epidemiológicos diferentes; de transmisión esporádica, de transmisión estable y de transmisión en expansión, como en el caso de Argentina, Paraguay y Brasil. Sin embargo, en Chile y Uruguay hasta el año 2017 no se habían reportado casos autóctonos en humanos (24). En Uruguay no se había detectado el insecto vector de la leishmaniasis hasta el año 2010, cuando el vector Lutzomyia longipalpis fue capturado por primera vez en el norte del país, en los departamentos de Artigas (Bella Unión) y Salto, aunque en el resto de América esta enfermedad en animales y humanos ya era endémica. En el año 2015 se constataron los primeros casos de perros con leishmaniasis por Leishmania infantum en canes del paraje Arenitas Blancas en el departamento de Salto (25).

Desde entonces, siguiendo las recomendaciones de la OPS, los servicios de salud trabajaron conjuntamente con la participación del Sistema Nacional de Emergencias y los Comités de Emergencia Departamentales en el seguimiento y control de los perros afectados, lo cual implicó el sacrificio de varios de ellos. Las personas que debían sacrificar a sus animales lo hicieron, lo que se tomó como una demostración del éxito de la sensibilización sobre el tema. Sin embargo, el riesgo mayor se encuentra en los perros callejeros que son frecuentes en los lugares donde prolifera el flebótomo. Ante esta situación de riesgo inminente de aparición de casos humanos, la División 
de Epidemiología del MSP conformó un equipo multidisciplinario, con la participación de la UDELAR, para el desarrollo de guías de manejo de Leishmaniasis visceral en el humano, vector, reservorio y comunicación, destacando los principales lineamientos de actuación en nuestro país. Se insistió en la responsabilidad de los dueños respecto del control y monitoreo de sus mascotas y el trabajo en la zona donde se confirmó el caso, en procura de disminuir las condiciones ambientales que favorecen la proliferación del vector, ya que el insecto requiere humedad y sombra, factores muy frecuentes en el litoral y noroeste del país (26).

Si bien el insecto vector de la leishmaniasis se encuentra en Salto y Artigas desde el año 2010, no se habían registrado casos autóctonos en humanos; el primer caso confirmado se registró el 5 de diciembre de 2018, en un menor salteño que se encontraba en buenas condiciones de salud. Se trataba de un paciente de 4 años de edad, que presentó una buena evolución con el tratamiento instituido (27).

Como consecuencia de la detección de este primer caso autóctono, el MSP puso en marcha las acciones que prevé la "Guía de diagnóstico, tratamiento y control de la Leishmaniasis visceral en Uruguay" (28). En el año 2019, el 22 de enero, se detectó el segundo caso autóctono en un paciente de 33 años en el mismo departamento. Paciente que presentaba varias enfermedades crónicas lo que condicionó una mala respuesta al tratamiento, provocándole la muerte (29).

Ante esta situación, un equipo de epidemiología trabajó nuevamente en la zona para completar la investigación y coordinar acciones junto a autoridades y técnicos departamentales. Entre ellas, la búsqueda y control del insecto transmisor de leishmaniasis y la profundización de las acciones que se vienen llevando a cabo para el control de la enfermedad en los perros, con el apoyo de la OPS y la Facultad de Medicina, UDELAR (27). Enmarcado en la estrategia de control de la leishmaniasis en el norte de Uruguay, en abril del
2019, un equipo del MSP y de la Comisión de Zoonosis, recorrió varias manzanas del barrio Cerro en la ciudad de Salto, zona en la que se detectaron varios perros infectados de leishmaniasis y dos casos autóctonos de esa enfermedad en humanos. El objetivo de la visita era realizar análisis de sangre a los canes del área. De este estudio de prevalencia realizado, que implicó la extracción de sangre a los animales, previo consentimiento de sus dueños, surgió que, de 70 perros analizados, ocho portaban la patología. Al no existir tratamientos efectivos para los perros infectados, que son los portadores de la enfermedad la única solución es sacrificarlos, aunque hay quienes se encariñan con el animal de compañía. En ese contexto, los abogados de los ministerios del Interior, de Ganadería, Agricultura y Pesca y de Salud Pública redactaron una ordenanza por la cual se puede solicitar a un juez una orden de allanamiento para ingresar en el domicilio de quien se niegue a que se realice el estudio a su perro. También se podrá solicitar una orden al juez para los propietarios de animales que sean positivos de leishmaniasis y no se comprometan a realizar los cuidados necesarios para que el perro no enferme a otras personas (30). Como la enfermedad, por ahora está localizada en Bella Unión (Artigas) y el departamento de Salto, las autoridades nacionales solicitaron a los veterinarios que realicen un asesoramiento responsable sobre el tema, por el impacto que tiene en los perros, dado que es una enfermedad que no tiene cura, y por su contagio en humanos, que en algunos casos puede ser letal. El $87 \%$ de los dueños de los animales acepta sacrificar a su perro cuando da positivo a la enfermedad, atendiendo a los riesgos que implica no hacerlo (31).

La campaña de control y prevención se basa en recordarle a la población que esta es una enfermedad que depende mucho de las conductas. Salto y Bella Unión deben ser las ciudades más limpias y cuidadas del país, es una manera de evitar la difusión del vector y que este se acerque a los perros. 


\section{CONTROL Y PREVENCIÓN}

El principal objetivo de la campaña es generar conciencia sobre las medidas que la población puede adoptar para el combate de este insecto. La higiene en el domicilio, el cuidado y limpieza de ciudades y los poblados son las principales medidas a tener en cuenta.

También es importante evitar las picaduras de insectos en personas y perros, usar repelente y ropa protectora que cubra brazos y piernas, colocar mosquiteros en puertas y ventanas de las casas, retirar residuos de poda, césped cortado y otros cúmulos de materia orgánica para disminuir la presencia del vector.

Como el perro es el principal reservorio de los parásitos que provocan la leishmaniasis, se aconseja el sacrificio de los perros infectados. Se recomienda a quienes tienen mascotas, realizar un control sanitario periódico y solicitar una prueba de la enfermedad en cachorros de más de 4 meses o de los padres si tienen menos edad (32).

La vigilancia eficaz de la enfermedad es importante. La notificación rápida de datos es fundamental para el monitoreo y la adopción de medidas durante las epidemias y las situaciones en las que hay una elevada tasa de letalidad aun con tratamiento. La movilización social y el fortalecimiento de alianzas, movilizar e informar a las comunidades a través de intervenciones efectivas para modificar las pautas de comportamiento mediante estrategias de comunicación adaptadas a la situación local. Las alianzas y la colaboración con diferentes sectores interesados y otros programas de lucha contra enfermedades transmitidas por vectores son esenciales a todos los niveles.

\section{Medidas para Salto y Bella Unión}

"Ministerio de Salud Pública estudia compra de collares que previenen la leishmaniasis en zonas donde circula el vector. Ante el éxito de la campaña contra la leishmaniasis en Brasil, donde la enfermedad se encuentra más extendida que en Uruguay, el Ministerio de Salud Pública analiza la implementación de una de las medidas del país norteño sobre la cual hay probada evidencia científica: la adquisición de collares con deltametrina, una sustancia que repele al flebótomo que contagia la enfermedad de perros a humanos" (32). Son pocos los caninos que tienen collar con "deltametrin", por lo que el ministerio trabaja para concretar la compra de una determinada cantidad de collares que puedan ser distribuidos entre los hogares que tengan perros y no puedan adquirirlos. Si la compra se decide favorablemente, sería a través de la OPS. La experiencia de Brasil, donde se concentra el $95 \%$ de los casos de leishmaniasis se implementó la distribución de collares con esta sustancia y la evidencia científica demuestra que es un mecanismo de prevención exitoso, ya que no solo repele a la mosquita, sino que además mata al insecto. En el resto del país, se buscó el vector, sobre todo en los territorios cercanos a las zonas de circulación, y hasta ahora no apareció. De todas formas, durante el invierno no se pueden hacer las capturas porque no se encuentran, ya que los huevos y larvas no prosperan y quedan a la espera de mejores temperaturas. Es así que los adultos no tienen actividad. Está previsto que la búsqueda se retome en primavera (33).

\section{VIGILANCIA EPIDEMIOLÓGICA EN EL HOMBRE}

Notificación: es obligatorio reportar todo caso sospechoso a la División Epidemiológica del MSP (Decreto 41/012) (34).

\section{VIGILANCIA EPIDEMIOLÓGICA EN ANIMALES}

Notificación: a la autoridad competente. Evento sanitario de riesgo que se presente en forma inusitada.

- Información a la población.

- Promoción de hábitos para prevenir picaduras de vectores.

- Hábitos de higiene ambiental para disminuir los sitios de proliferación de flebótomos como eliminación correcta de residuos, limpiar el terreno al- 
rededor de la vivienda para mantenerlo libre de malezas, escombros, hojarasca o acumulación de deshechos de animales domésticos.

- Vigilancia y control del vector.

- Vigilancia y control de reservorios.

- Estar atentos para realizar la consulta veterinaria si la mascota (perro) presenta: caída del pelo especialmente alrededor de ojos y orejas, fatiga, pérdida de peso, seborrea escamosa (semejante a caspa), crecimiento exagerado de las uñas, úlceras de piel, hemorragia nasal (2).

\section{"MGAP: Información al turista - Comercio Internacional - Sanidad Animal}

Para el caso de caninos, Uruguay NO autorizará la entrada a su territorio de animales previamente diagnosticados con leishmaniosis. Se recuerda que a partir del 01/04/2017 se exigirá la prueba de detección de la respuesta inmunitaria negativa a leishmaniasis, de acuerdo al "Manual de las Pruebas de Diagnóstico y de las Vacunas para los animales terrestres" de la Organización Mundial de Sanidad Animal (OIE) entre otros, para ingreso al país de animales de la especie canina, provenientes de países o zonas con leishmaniasis" (35).

\section{DECLARACIÓN DE CONFLICTOS DE INTERESES:}

Los autores no reportan ningún conflicto de interés. El estudio se realizó con recursos propios de los autores y/o la institución a la que representan.

\section{REFERENCIAS}

(1) Herwaldt B L. Leishmaniasis. Lancet 1999; 354(9185):1191-9. doi: 10.1016/S0140-6736(98)10178-2

(2) Organización Panamericana de la Salud. Organización Mundial de la Salud. Prevención y Control de la Hidatidosis en el Nivel Local: iniciativa sudamericana para el control y vigilancia de la equinococosis quística / hidatidosis.

Río de Janeiro : PANAFTOSA-OPS/OMS, 2017. p. 27-29. Disponible en: https://iris. paho.org/bitstream/handle/10665.2/34173/01016970MT18-spa.pdf?sequence=6\&isAllowed=y [Consulta 13/05/2019].

(3) Organización Panamericana de la Salud. Información general: Leishmaniasis.

Disponible en: https://www.paho.org/hq/index.php? option=com_content\&view=article\&id=9417:2014-informacion-general-leishmaniasis\&ltemid=40370\& lang=es [Consulta 06/06/2019].

(4) Solano-Gallego L. Leishmaniosis.

Una revisión actualizada.

Zaragoza : Cervet, 2013. p. 3.

(5) Organización Mundial de la Salud. Control de las Leishmaniasis: informe de una reunión del Comité de Expertos de la OMS sobre el control de las Leishmaniasis, Ginebra, 22-26 Marzo de 2010. Publicación № 949. Ginebra: OMS, 2012. Disponible en: https://apps.who.int/iris/bitstream/ handle/10665/82766/WHO_TRS_949_spa.pdf? sequence=1\&isAllowed=y [Consulta 06/06/2019].

(6) Organización Panamericana de la Salud. Manual de procedimientos para vigilancia y control de las leishmaniasis en las Américas.

Washington, D.C.: OPS; 2019.

Disponible en: https://iris. paho.org/bitstream/handle/10665.2/50524/9789275320631_spa.pdf?sequence=1\&isAllowed=y [Consulta 06/06/2019]. 
(7) Uruguay. Ministerio de Salud Pública. Guía de diagnóstico, tratamiento y control de la Leishmaniasis visceral en Uruguay. Montevideo: MSP, 2016.

Disponible en: file:///C:/Users/pc/Desktop/guia_ leishmaniasis_visceral_en_uruguay.pdf [Consulta 08/06/2019].

(8) Center for Food Security and Public Health. lowa State University.

Leishmaniasis (cutánea y visceral). 13 p. 2009.

Disponible en: http://www.cfsph.iastate.edu/Factsheets/ es/leishmaniasis-es.pdf [Consulta 08/06/2019].

(9) Ready PD. Biology of phlebotomine sand flies as vectors of disease agents.

Annu Rev Entomol 2013; 58:227-50.

doi: 10.1146/annurev-ento-120811-153557

(10) Ruiz Villareal M.

Life cycle of the parasites from the genus Leishmania, the cause of the disease Leishmaniasis. From Wikimedia Commons, the free media repository 2008. Available from: https://commons. wikimedia.org/wiki/File:Leishmaniasis_life_cycle_diagram_en.svg\#/media/File:Leishmaniasis_ life_cycle_diagram-es.svg [Consulted 20/06/2019].

(11) Organización Mundial de la Salud.

Nota descriptiva 2017: Leishmaniasis.

Disponible en: https://www.who.int/es/news-room/factsheets/detail/leishmaniasis [Consulta 20/06/2019].

(12) Miro G, Fraile C, Frisuelos C.

Zoonosis en pequeños animales.

Canis et felis 2001; 50:85-108.

Disponible en: https://es.scribd.,/document/36009 9088/Zoonosis-en-pequeños-animales-pdf

[Consulta 20/06/2019].

(13) Desjeux P.

Leishmaniasis: current situation and new perspectives. Comp Immunol Microbiol Infect Dis 2004; 27(5):305-18. doi: 10.1016/j.cimid.2004.03.004

(14) Organización Mundial de la Salud.

Imágenes para descargar sobre la Leishmaniasis. Disponible en: https://www.who.int/campaigns/worldhealth-day/2014/photos/leishmaniasis3.jpg?ua=1 [Consulta 10/06/2019].
(15) Desjeux P.

Global control and Leishmania HIV co-infection.

Clin Dermatol 1999; 17(3):317-25.

doi: 10.1016/s0738-081x(99)00050-4

(16) Solano-Gallego L. Leishmaniosis.

Una revisión actualizada.

Zaragoza : Cervet, 2013. p. 55-57.

(17) Solano-Gallego L, Koutinas A, Miro G, Cardoso L, Pennisi MG, Ferrer L, et al.

Directions for the diagnosis, clinical staging, treatment and prevention of canine leishmaniosis.

Vet Parasitol 2009; 165(1-2):1-18.

doi: 10.1016/j.vetpar.2009.05.022

(18) Ciaramella P, Oliva G, Luna RD, Gradoni L, Ambrosio R, Cortese L, Scalone A, Persechino A. A retrospective clinical study of canine leishmaniasis in 150 dogs naturally infected by Leishmania infantum. Vet Rec 1997; 141(21):539-543.

doi: 10.1136/vr.141.21.539

(19) Koutinas AF, Scott DW, Kantos B, Lekkas S. Skin lesions in canine Leishmaniosis (kala-azar): A clinical and histopathological study on 22 spontaneous cases in Greece. Vet Dermatol 1992; 3(3):121-130. https://doi.org/10.1111/j.1365-3164.1992.tb00158.x

(20) Ferrer L, Rabanal R, Fondevila D, Ramos JA, Domingo M. Skin lesion in canine Leishmaniasis. J Small Anim Pract 1988; 29(6):381-388.

https://doi.org/10.1111/j.1748-5827.1988.tb02298.x

(21) Koutinas AF, Carlotti DN, Koutinas C,

Papadogiannakis EI, Spanakos GK,

Saridomichelakis MN.

Claw histhopatology and parasitic load in natural cases of canine Leishmaniosis asossiated with Leishmania infantum.

Vet Dermatol 2010; 21(6):572-7.

doi: 10.1111/j.1365-3164.2009.00863.x

(22) Solano -Gallego L, Koutinas A, Miró G, Cardoso L, Pennisi M, Ferrer L, et al.

LeishVet guidelines for the practical management of canine leishmaniasis. Parasit Vectors 2011; 4:86. doi:10.1186/1756-3305-4-86 
(23) Saridomichelakis MN. Advances in the pathogenesis of canine Leishmaniosis epidemiologic and diagnostic implication.

Vet Dermatol 2009; 20(5-6):471-89.

doi: 10.1111/j.1365-3164.2009.00823.x

(24) Baneth G, Shaw SE. Chemoteraphy of canine Leishmaniosis. Vet Parasitol 2002; 106(4):315-24. doi: 10.1016/s0304-4017(02)00115-2

(25) Grill F, Zurmendi M. Leishmaniasis visceral en el Uruguay. Arch Pediatr Urug 2017; 88(1):32-38.

(26) Satragno D, Faral-Tello P, Canneva B, Verger L, Lozano A, Vitale E, et al.

Autochthonous Outbreak and Expansion of Canine Visceral Leishmaniasis, Uruguay.

Emerg Infect Dis 2017; 23(3):536-538.

doi: $10.3201 /$ eid2303.160377

(27) Uruguay. Ministerio de Salud Pública. Uruguay registra primer caso de leishmaniasis en humanos en un continente donde el mal es endémico.

6 de diciembre de 2018.

Disponible en: https://www.gub.uy/ministerio-salud-publica/comunicacion/noticias/uruguay-registra-primer-caso-de-leishmaniasis-en-humanos-en-un-continente [Consulta 14/07/2019].

(28) Uruguay. Ministerio de Salud Pública. Primer caso de Leishmaniasis en humanos en Uruguay. Comunicado de prensa.

Disponibleen:https://www.elpais.com.uy/informacion/ salud/primera-vez-confirmo-uruguay-caso-leishmaniasis-visceral-humano.html [Consulta 14/07/2019].

(29) MSP confirmó un caso de leishmaniasis visceral en un niño que vive en Salto.

Diario El Observador 05 de diciembre de 2018. Disponible en: https://www.elobservador.com.uy/ nota/msp-confirmo-un-caso-de-leishmaniasis-visc eral-en-un-nino-residente-en-salto-201812521919 [Consulta 14/07/2019].
30) Confirmaron segundo caso de leishmaniasis en un humano en Uruguay.

Diario El País 22 de enero de 2019.

Disponible en: https://www.elpais.com.uy/informacion/salud/confirman-segundo-caso-leishmaniasis-humano-uruguay.html [Consulta 14/07/2019].

31) Uruguay. Ministerio de Salud Pública. Ocho perros de 70 analizados dieron positivo en comienzo de estudio de prevalencia de leishmaniasis en Salto. Comunicado de prensa.

Disponible en: https://www.gub.uy/ministerio-saludpublica/comunicacion/noticias/ocho-perros-de-70analizados-dieron-positivo-en-comienzo-de-estudio-de [Consulta 12/07/2019].

32) Uruguay. Ministerio de Salud Pública. Salud Pública estudia compra de collares que previenen la leishmaniasis en zonas donde circula el vector. Comunicado de prensa.

Disponible en: https://www.gub.uy/ministerio-saludpublica/comunicacion/noticias/salud-publica-estudia-compra-collares-previenen-leishmaniasis-zonas-circula [Consulta 12/07/2019].

33) Uruguay. Ministerio de Salud Pública. Prevención de leishmaniasis en Artigas. Comunicado de prensa. Disponible en: https://www.gub.uy/ministerio-saludpublica/comunicacion/noticias/prevencion-de-leishmaniasis-en-artigas [Consulta 12/07/2019].

34) Uruguay. IMPO. Diario oficial. 28 de febrero de 2012. Decreto $N^{\circ} 41 / 012$.

Disponible en: https://www.impo.com.uy/bases/ decretos/41-2012 [Consulta 12/07/2019].

35) Uruguay. Ministerio de Ganadería Agricultura y Pesca. Resolución No 374/016 de DGSG de 29/11/2016. Disponible en: https://www.gub.uy/ ministerio-ganaderia-agricultura-pesca/institucional/normativa/resolucion-374016-dgsg-29112016 [Consulta 12/07/2019]. 